\title{
Effect of restrictive versus liberal transfusion strategies on outcomes in patients with cardiovascular disease in a non-cardiac surgery setting: systematic review and meta-analysis
}

\begin{abstract}
Annemarie B Docherty, ${ }^{1,2}$ Rob O'Donnell, ${ }^{2}$ Susan Brunskill, ${ }^{3}$ Marialena Trivella, ${ }^{3}$ Carolyn Doree, ${ }^{4}$ Lars Holst, ${ }^{5}$ Martyn Parker, ${ }^{6}$ Merete Gregersen, ${ }^{7}$ Juliano Pinheiro de Almeida, ${ }^{8}$ Timothy S Walsh, ${ }^{1,2}$ Simon J Stanworth 3,9
\end{abstract}

\section{ABSTRACT}

OBJECTIVE

To compare patient outcomes of restrictive versus liberal blood transfusion strategies in patients with cardiovascular disease not undergoing cardiac surgery.

DESIGN

Systematic review and meta-analysis.

\section{DATA SOURCES}

Randomised controlled trials involving a threshold for red blood cell transfusion in hospital. We searched (to 2 November 2015) CENTRAL, Medline, Embase, CINAHL, PubMed, LILACS, NHSBT Transfusion Evidence Library, ClinicalTrials.gov, WHO International Clinical Trials Registry Platform, ISRCTN Register, and EU Clinical Trials Register. Authors were contacted for data whenever possible.

\section{TRIAL SELECTION}

Published and unpublished randomised controlled trials comparing a restrictive with liberal transfusion threshold and that included patients with cardiovascular disease.

\section{DATA EXTRACTION AND SYNTHESIS}

Data extraction was completed in duplicate. Risk of bias was assessed using Cochrane methods. Relative risk ratios with $95 \%$ confidence intervals were presented in all meta-analyses. Mantel-Haenszel random effects models were used to pool risk ratios.

\section{WHAT IS ALREADY KNOWN ON THIS TOPIC}

Restrictive red cell transfusion policies are recommended as safe for most hospital patients with anaemia

Uncertainty exists for patients with cardiovascular disease, whose hearts may be more susceptible to limited coronary oxygen supply

No systematic reviews have specifically compared outcomes for patients with cardiovascular disease in a non-cardiac surgery setting, and guidelines acknowledge the paucity of evidence in this area

\section{WHAT THIS STUDY ADDS}

Restrictive blood transfusion strategies may not be as safe as more liberal strategies for patients with coexisting cardiovascular disease in non-cardiac surgery settings

An increased risk of acute coronary syndrome was shown with restrictive thresholds (haemoglobin level $<80 \mathrm{~g} / \mathrm{L}$ )

These data support the use of a more liberal transfusion threshold $(>80 \mathrm{~g} / \mathrm{L})$ for patients with both acute and chronic cardiovascular disease, until adequately powered high quality randomised trials have been undertaken in this patient population

\section{MAIN OUTCOME MEASURES}

30 day mortality, and cardiovascular events.

\section{RESULTS}

41 trials were identified; of these, seven included data on patients with cardiovascular disease. Data from a further four trials enrolling patients with cardiovascular disease were obtained from the authors. In total, 11 trials enrolling patients with cardiovascular disease $(\mathrm{n}=3033)$ were included for meta-analysis (restrictive transfusion, $n=1514$ patients; liberal transfusion, $\mathrm{n}=1519)$. The pooled risk ratio for the association between transfusion thresholds and 30 day mortality was 1.15 (95\% confidence interval 0.88 to 1.50 , $\mathrm{P}=0.50)$, with little heterogeneity $\left(\mathrm{I}^{2}=14 \%\right)$. The risk of acute coronary syndrome in patients managed with restrictive compared with liberal transfusion was increased (nine trials; risk ratio $1.78,95 \%$ confidence interval 1.18 to $2.70, \mathrm{P}=0.01, \mathrm{I}^{2}=0 \%$ ).

\section{CONCLUSIONS}

The results show that it may not be safe to use a restrictive transfusion threshold of less than $80 \mathrm{~g} / \mathrm{L}$ in patients with ongoing acute coronary syndrome or chronic cardiovascular disease. Effects on mortality and other outcomes are uncertain. These data support the use of a more liberal transfusion threshold ( $>80$ $\mathrm{g} / \mathrm{L})$ for patients with both acute and chronic cardiovascular disease until adequately powered high quality randomised trials have been undertaken in patients with cardiovascular disease.

\section{REGISTRATION}

PROSPERO CRD42014014251.

\section{Introduction}

Approximately seven million people in the United Kingdom have cardiovascular disease,${ }^{1}$ and it is a prevalent comorbidity among patients admitted to hospital. In observational studies, anaemia is associated with worse outcomes in patients who have both acute and chronic cardiovascular disease, but it is unclear whether this association is causal or whether correction with red blood cell transfusions modifies this relation..$^{2-5}$ Anaemia decreases the oxygen content of the blood supplied to the myocardium and may increase myocardial oxygen demand because a higher cardiac output is required to maintain adequate systemic oxygen delivery. ${ }^{6}$ The heart extracts a high proportion of the oxygen supplied through the coronary arteries, and therefore this circulation is potentially at higher risk 
from the combination of atheroma related flow limitation and anaemia. Hypotension, tachycardia, and the requirement for catecholamine use (for example, during critical illness or major surgery) can further compromise the balance between oxygen supply and demand, resulting in myocardial injury. This has been termed type 2 myocardial infarction. ${ }^{7}$ The release of troponin, a biomarker of myocardial injury, is associated with higher mortality in critically ill and perioperative populations..$^{8-10}$

Systematic reviews of randomised trials of liberal versus restrictive blood transfusion strategies support a general default trigger threshold for haemoglobin levels of around $70 \mathrm{~g} / \mathrm{L}$ for most patient groups, ${ }^{11-13}$ and this is reflected in recent guidelines advocating restrictive use of blood transfusions. ${ }^{14-17}$ These guidelines have highlighted the lack of evidence and uncertainty about best practice for patients with acute or chronic cardiovascular disease. ${ }^{14-17}$ No systematic reviews have specifically compared outcomes for patients with chronic cardiovascular disease undergoing non-cardiac surgery, or other treatments such as intensive care. A recent systematic review restricted to patients undergoing cardiac surgery suggested better outcomes with more liberal transfusions, highlighting the potentially important interaction between anaemia, blood transfusions, and outcomes for patients with cardiovascular disease. ${ }^{18}$ The National Institute for Health and Care Excellence guideline on blood transfusion, published in November 2015, stated that the optimal transfusion threshold for patients with ongoing acute coronary syndrome was 80-100 g/L, but it made no specific recommendation for patients with chronic cardiovascular disease and highlighted the need for further research in this specific population. ${ }^{19}$

We conducted a systematic review and meta-analysis assessing the effect of restrictive versus liberal red cell transfusion strategies on patient outcomes restricted to adults with cardiovascular disease, excluding those who had cardiac surgery.

\section{Methods}

This systematic review was conducted according to the protocol registered with PROSPERO. We followed methods defined in the preferred reporting items for systematic reviews and meta-analyses statement. ${ }^{20}$

\section{Eligibility criteria}

We included only randomised controlled trials. Trials were eligible for inclusion if they evaluated the effectiveness of any policy involving the use of a trigger or transfusion threshold based on haemoglobin concentration (including haematocrit) for guiding allogeneic red cell transfusion. Control group patients were required to receive transfusion at a higher haemoglobin concentration or haematocrit. We considered trials including adults ( $\geq 18$ years) except those who had undergone cardiac surgery as this is a distinct group of patients with a clinically significantly altered cardiovascular risk as a result of the procedure. ${ }^{21}$ We excluded children and neonates owing to the low prevalence of cardiovascular disease.
In our protocol we defined cardiovascular disease as known coronary artery disease (acute coronary syndrome, chronic ischaemic heart disease) or other cardiovascular disease (cerebrovascular accident, transient ischaemic attack, peripheral vascular disease). We defined acute coronary syndrome as ST elevation myocardial infarction, non-ST elevation myocardial infarction, or unstable angina. Supplementary table E1 summarises the definitions for cardiovascular disease used by the authors of included trials.

\section{Search strategy}

We did not restrict our search by language, date, or publication status. We updated a search strategy we conducted in September 2009, reviewing the overall use of red blood cell transfusions. ${ }^{22}$ The present search included two changes: in CENTRAL there was a date restriction, and in Medline and Embase the following search method was used: the original search strategies+original randomised controlled trial filters were rerun up until the end of 2008; the new strategies+new randomised controlled trial filters were run for all years; the results of rerunning the original search strategies+original randomised controlled trial filter until 2009 were then removed from the new search results. Once all the search results had been downloaded into bibliographic software, we removed all previously screened references from the overview of the use of red blood cell transfusion, along with any duplicates. The search strategies are available in the online data supplement.

The date of the last search was 2 November 2015 for the following databases: CENTRAL (Cochrane Library issue 8, 2014): publication years 2009-14; Medline (1946 onwards); Embase (1974 onwards); CINAHL (1937 onwards); PubMed (epublications only); LILACS (200914); Transfusion Evidence Library (1980 onwards); and Web of Science (Conference Proceedings Citation Index-Science, 1990 to present).

We searched for ongoing studies in five registries: ClinicalTrials.gov, WHO international clinical trials registry platform, ISRCTN register, European Union clinical trials register (www.clinicaltrialsregister.eu/ ctr-search), and the Hong Kong clinical trials registry. All sites were searched on 2 November 2015. Supplementary appendix 1 details the search strategies.

\section{Data extraction}

Trial selection

Two authors (AD and RO) independently reviewed all identified titles and abstracts against the prespecified eligibility criteria. Disagreements were resolved by discussion with the other authors. We considered all publications reporting a randomised controlled trial that used a valid transfusion threshold and where inclusion criteria indicated patients with cardiovascular disease. We contacted the authors of eligible trials that included cardiovascular subgroups or a high proportion of patients with cardiovascular disease and requested data for these patients. For trials that included patients both with and without cardiovascular disease, we 
ascertained whether randomisation was stratified by the presence or absence of cardiovascular disease.

Data were extracted using a form piloted before the study. Two authors (AD and RO) independently extracted data on trial characteristics, primary and secondary outcomes, cardiac specific morbidity, and general morbidity. A third author (SS) checked for discrepancies between the independent data extraction, and disagreements were resolved by discussion between the three authors. Our primary outcome was mortality at 30 days. We also extracted mortality data at 60 days, mortality during intensive care unit or hospital stay, and other mortality as defined by the authors.

Wherever possible we categorised data on cardiovascular events as acute coronary syndrome, acute pulmonary oedema, peripheral ischaemia, and thrombotic events. The category of acute coronary syndrome included myocardial infarction, acute coronary syndrome, and cardiac arrest.

Measures of general morbidity were use of packed red blood cells, adverse reactions to transfusion, incidence of in-hospital infections, measures of organ dysfunction, duration of intensive care unit or hospital stay, invasive ventilation, haemodynamic support, and renal support.

\section{Risk of bias assessment}

We assessed the risk of bias using the method outlined in the Cochrane Collaboration Handbook for Systematic Reviews of Interventions. ${ }^{23}$ Risk of bias was assessed as high, low, and unclear for each of selection bias, performance bias, detection bias, attrition bias, and reporting bias. We specifically assessed blinding for the outcomes of cardiovascular events.

\section{Grading quality of evidence}

We assessed the quality of evidence for mortality, acute coronary syndrome, and acute pulmonary oedema according to GRADE methods for risk of bias, inconsistency, indirectness, imprecision, and publication bias. These were classified as very low, low, moderate, or high. ${ }^{24}$

\section{Data synthesis and analysis}

All statistical analyses were performed using Review Manager 5.25 Meta-analysis was undertaken where data were sufficient. We used a random effect model as we anticipated that there would be substantial clinical heterogeneity. We reported relative risk ratios for dichotomous outcomes, with $95 \%$ confidence intervals. Median and interquartile ranges described non-parametric measures.

We included one cluster randomised trial. ${ }^{26}$ However, we had no information on which clusters the patients with cardiovascular disease were in, and the intraclass correlation coefficient was 0.001 for mortality, suggesting that only $0.1 \%$ of the variance was due to the effect of the trial site and $99.1 \%$ to differences between patients. We performed a sensitivity analysis without taking the clustering into account, and this did not alter our results. These data were therefore included as unique patient data.

\section{Assessment of heterogeneity}

Assessment of clinical heterogeneity included consideration of participant characteristics (eg, acute coronary syndrome versus chronic cardiovascular disease) and the clinical setting (critical care versus orthopaedics versus acute coronary syndrome). We undertook a subgroup analysis of patients with chronic cardiovascular disease, excluding trials including patients with ongoing acute coronary syndromes. Data were insufficient to undertake the preplanned subgroup analyses of critical care trials or of acute coronary syndromes.

We assessed statistical heterogeneity of treatment effects between trials using the $\chi^{2}$ test. The $\mathrm{I}^{2}$ statistic was used to quantify the percentage of variability that was due to heterogeneity (we defined heterogeneity of $>50 \%$ as moderate and $>80 \%$ as substantial).

\section{Patient involvement}

No patients were involved in setting the research question or the outcome measures, nor were they involved in the design and implementation of the study. There are no plans to involve patients in the dissemination of the results.

\section{Results}

\section{Search results}

Figure 1 shows the flow of studies through the review. The search retrieved 9462 results (of which 283 were ongoing randomised controlled trials), which were reduced to 6520 results once duplicates were removed. After removal of previously screened references, 3955 titles and abstracts ( 3832 completed trials and 123 ongoing

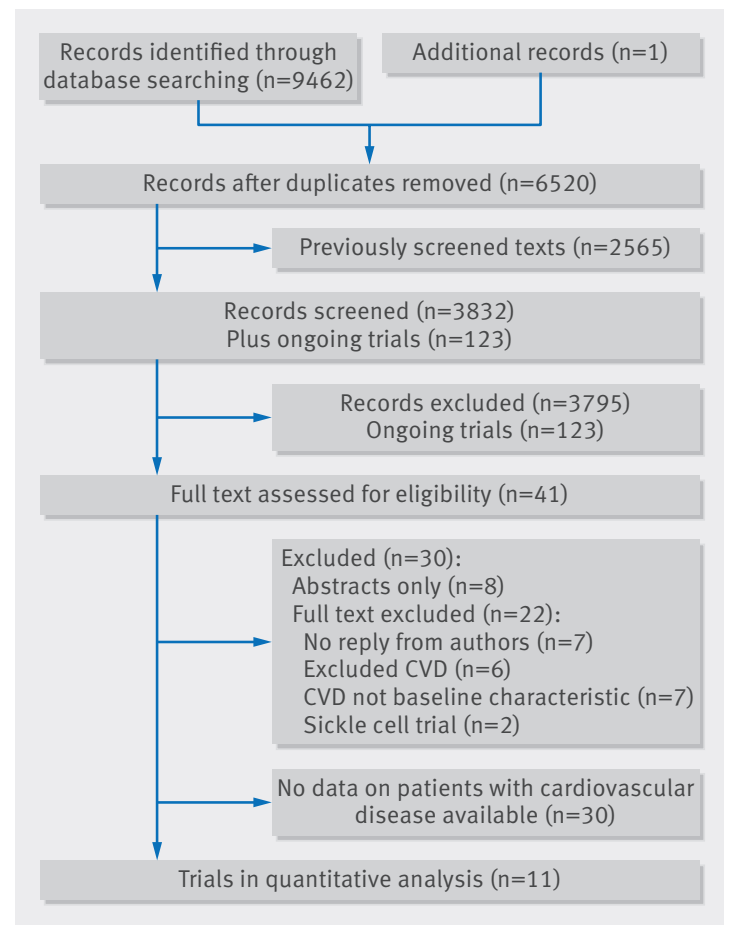

Fig 1 | PRISMA flow diagram. CVD=cardiovascular disease 
randomised controlled trials) were screened for eligibility. Of these, 41 completed trials were eligible for full text screening (with five of the ongoing trials being potentially eligible for inclusion on their completion). ${ }^{27-31}$

Thirty trials were ineligible for inclusion. Six excluded patients with signs or symptoms of heart disease, cardiac disease with New York Heart Association Class (NYHA) II or above, and American Society of Anesthetists class (ASA) II or worse. ${ }^{32-37}$ Two trials targeted preoperative haemoglobin S levels in sickle cell anaemia and were therefore not relevant. ${ }^{38} 39$ Seven full text trials ${ }^{40-46}$ and eight abstracts ${ }^{27}$ 47-53 did not include cardiovascular disease as a baseline characteristic.

From the 41 potentially eligible trials, we were able to extract data on patients with cardiovascular disease from seven $(n=2796) .2654-59$ One of these trials published 30 day mortality data for patients with cardiovascular disease, and the authors responded to our request for further data on cardiovascular outcomes and general morbidity outcomes $(n=32) .59$ From reported baseline demographic data we were aware that patients with cardiovascular disease were included in 11 further trials, ${ }^{60-70}$ but we were unable to extract any relevant data directly from the published text. After contact with the authors for any data on patients with cardiovascular disease in their trials, we were able to include data from four trials. ${ }^{66-69}$ We did not contact the authors of the seven trials and eight abstracts that did not mention cardiovascular disease as a baseline characteristic in their trial. ${ }^{27} 40-53$ Characteristics of all 29 eligible trials that are not included in this review can be found in supplementary table E1. In this review we included 11 transfusion threshold trials involving patients with cardiovascular disease $(\mathrm{n}=3033)$.

\section{Trial characteristics}

The setting of the 11 included trials varied: orthopaedics $(n=3), 556669$ upper gastrointestinal bleeding $(n=1),{ }^{26}$ acute coronary syndrome or myocardial infarction $(n=2), 5657$ critical care $(n=4), 58596768$ and elective aortic and infra-inguinal revascularisation $(\mathrm{n}=1) . .^{54}$

Definitions of cardiovascular disease differed between trials (see supplementary table E1). Other than one trial of elective aortic and infra-inguinal revascularisation, ${ }^{54}$ all trials included patients with a diagnosis of ischaemic heart disease, and all but the two acute myocardial infarction trials ${ }^{5657}$ included patients with congestive cardiac failure. Other trials also included risk factors for ischaemic heart disease, including peripheral vascular disease, ${ }^{545558666770}$ cerebrovascular disease, ${ }^{55666768}$ diabetes, ${ }^{66}$ and hypertension. ${ }^{66}$ Trials varied from all patients having cardiovascular disease ${ }^{54-57}$ to predefined cardiovascular disease subgroups, ${ }^{265868}$ to high proportions of patients with cardiovascular disease. ${ }^{59666769}$ Included trials were both multicentre $(n=7)^{2655-5968}$ and single centre trials $(\mathrm{n}=4) .54666769$

Red cell transfusion thresholds varied. The lowest threshold for restrictive transfusion was $70 \mathrm{~g} / \mathrm{L}$ ( $\mathrm{n}=274$, from four trials) ${ }^{58596768}$ to $80 \mathrm{~g} / \mathrm{L}$ ( $\mathrm{n}=1125$, from three trials) ${ }^{26556}$ and $90 \mathrm{~g} / \mathrm{L}(\mathrm{n}=50)^{54}$ to $97 \mathrm{~g} / \mathrm{L}(\mathrm{n}=34) .{ }^{69} \mathrm{In}$ one trial transfusion was carried out only with symptoms of anaemia $(n=55)^{66}$ and in another by haematocrit concentration $(24 \%, n=24) .57$ Thresholds for liberal transfusion also varied considerably: the most common were $90 \mathrm{~g} / \mathrm{L}$ ( $\mathrm{n}=290$, from four trials) 58596768 and $100 \mathrm{~g} / \mathrm{L}$ ( $n=1221$ from five trials). ${ }^{2654-5666}$ Other thresholds were haemoglobin level $113 \mathrm{~g} / \mathrm{L}(\mathrm{n}=25)^{69}$ and 30\% haematocrit $(n=21) .{ }^{57}$ Six out of the 11 trials used leucocyte reduced red blood cells. .5-57 596869

Through data extraction, we were able to identify unique data for patients with cardiovascular disease for 3033 participants from 11 trials. The sample sizes of these trials varied from $45^{57}$ to $2015 . .^{55}$ Of the 3033 patients with cardiovascular disease, 1514 were randomised to restrictive transfusion thresholds and 1519 to liberal transfusion thresholds. Six trials that included patients both with and without cardiovascular disease did not stratify their randomisation by the presence or absence of cardiovascular disease. ${ }^{122658666769}$ Table 1 describes the characteristics of all included trials.

\section{Comparison of exposure to transfusion strategy}

Duration of intervention from randomisation - the duration of exposure to the two strategies varied considerably. One trial maintained the haemoglobin threshold for one year post-randomisation, ${ }^{66}$ two trials for 30 days, ${ }^{6971}$ five trials until hospital discharge, ${ }^{2654-57}$ three trials until discharge from intensive care, ${ }^{5867} 68$ and one trial for up to 14 days. ${ }^{59}$

Exposure to allogenic blood-The requirements for red blood cell transfusion were extracted from six trials ${ }^{54-575966}$ (see supplementary table E3). For all six trials, patients in the restrictive transfusion arm were exposed to considerably less allogeneic blood than were patients in the liberal transfusion arm. In the restrictive transfusion arms, between $20.4 \% 0^{54}$ and $84.2 \%{ }^{66}$ of patients received no blood transfusions compared with a range of $0 \% 5766$ to $12 \% 0^{54}$ for the liberal transfusion arms. Among patients who did receive red blood cells, the number of transfused units was lower in the restrictive transfusion arms (range from median 0 (interquartile range $0-1)^{55}$ to a mean of 1.6 units (SD 2.0) $)^{57}$ compared with the liberal transfusion arms (range from a mean of 1.58 units (SD 1.13) $)^{56}$ to a mean of 2.5 units (SD 1.3))..$^{57}$

\section{Effects on outcomes}

Mortality

Data on mortality were available from all 11 trials. Thirty day mortality was given for all trials except one, which reported 28 day mortality. ${ }^{26}$ Overall, 144 deaths (9.5\%) occurred in the restrictive transfusion arms compared with $126(8 \%)$ in the liberal transfusion arms (pooled effect estimate: risk ratio $1.15,95 \%$ confidence interval 0.88 to $1.50, \mathrm{P}=0.50, \mathrm{I}^{2}=14 \%, 3033$ patients, fig 2). We performed a subgroup analysis, including only trials where the randomisation was stratified for cardiovascular disease, ${ }^{54-565759}$ and for this subgroup the relative risk was 0.96 (95\% confidence interval 0.58 to 1.59 , $\left.\mathrm{P}=0.87, \mathrm{I}^{2}=14 \%\right)$. The sensitivity analysis in which the two trials including patients with acute coronary 


\begin{tabular}{|c|c|c|c|c|c|}
\hline \multirow[b]{2}{*}{ Trials } & \multirow[b]{2}{*}{ Clinical setting } & \multicolumn{3}{|c|}{ Restrictive transfusion; liberal transfusion } & \multirow[b]{2}{*}{ Primary endpoint } \\
\hline & & Threshold & $\begin{array}{l}\text { No of } \\
\text { participants }\end{array}$ & $\begin{array}{l}\text { No (\%) of patients } \\
\text { with CVD }\end{array}$ & \\
\hline $\begin{array}{l}\text { Almeida 2013, Brazil (single } \\
\text { centre) }\end{array}$ & Oncology & $70 \mathrm{~g} / \mathrm{L} ; 90 \mathrm{~g} / \mathrm{L}$ & $101 ; 97$ & $22(21.8) ; 12(12.4)$ & $\begin{array}{l}\text { Composite death or severe } \\
\text { complications }\end{array}$ \\
\hline Bush 1997, USA (single centre) & $\begin{array}{l}\text { Elective vascular } \\
\text { surgery }\end{array}$ & $90 \mathrm{~g} / \mathrm{L} ; 100 \mathrm{~g} / \mathrm{L}$ & $50 ; 49$ & 50 (100); $49(100)$ & $\begin{array}{l}\text { Myocardial ischaemia, myocardial } \\
\text { infarction, death }\end{array}$ \\
\hline $\begin{array}{l}\text { Carson 2011, USA/Canada } \\
\text { (multicentre) }\end{array}$ & $\begin{array}{l}\text { Patients with hip } \\
\text { fracture and with CVD } \\
\text { or risk factors for CVD* }\end{array}$ & $\begin{array}{l}80 \mathrm{~g} / \mathrm{L} \text { or symptoms of } \\
\text { anaemia; } 100 \mathrm{~g} / \mathrm{L}\end{array}$ & 1009; 1007 & 1009 (100); 1007 (100) & 60 day mortality; walk unaided \\
\hline Carson 2013, USA (multicentre) & $\begin{array}{l}\text { Symptomatic coronary } \\
\text { artery disease* }\end{array}$ & $\begin{array}{l}8 \mathrm{~g} / \mathrm{dL} \text { or symptoms of } \\
\text { anaemia; } 10 \mathrm{~g} / \mathrm{dL}\end{array}$ & $55 ; 55$ & 55 (100); 55 (100) & $\begin{array}{l}\text { Composite: all cause mortality, } \\
\text { myocardial infarction, or unscheduled } \\
\text { coronary revascularisation }\end{array}$ \\
\hline Cooper 2011, USA (multicentre) & $\begin{array}{l}\text { Acute myocardial } \\
\text { infarction* }\end{array}$ & Haemotocrit: $<24 \% ;<30 \%$ & $24 ; 21$ & 24 (100); $21(100)$ & $\begin{array}{l}\text { Composite: In-hospital death, } \\
\text { recurrent myocardial infarction, new } \\
\text { or worsening congestive heart failure }\end{array}$ \\
\hline $\begin{array}{l}\text { Gregersen 2015, Denmark } \\
\text { (single centre) }\end{array}$ & $\begin{array}{l}\text { Frail elderly patients } \\
\text { with hip fracture* }\end{array}$ & $97 \mathrm{~g} / \mathrm{L} ; 113 \mathrm{~g} / \mathrm{L}$ & $116 ; 111$ & 34 (29.3); 25 (22.5) & Recovery from physical disabilities \\
\hline Hebert 1998, Canada (multicentre) & Critical care & $70 \mathrm{~g} / \mathrm{L} ; 90 \mathrm{~g} / \mathrm{L}$ & 418; 420 & 160 (38.2); 197 (46.9) & 30 day mortality \\
\hline $\begin{array}{l}\text { Holst 2014, Scandinavia } \\
\text { (multicentre) }\end{array}$ & Critical care* $^{\star}$ & $70 \mathrm{~g} / \mathrm{L} ; 90 \mathrm{~g} / \mathrm{L}$ & $502 ; 496$ & 75 (14.9); 66 (13.3) & 90 day mortality \\
\hline Jairath 2015, UK (multicentre) & $\begin{array}{l}\text { Upper gastrointestinal } \\
\text { haemorrhage }\end{array}$ & $80 \mathrm{~g} / \mathrm{L} ; 100 \mathrm{~g} / \mathrm{L}$ & $403 ; 533$ & $61(15 \%) ; 76(14 \%)$ & Feasibility \\
\hline Parker 2013, UK (single centre) & $\begin{array}{l}\text { Patients with hip } \\
\text { fracture }\end{array}$ & $\begin{array}{l}\text { Definite symptoms of } \\
\text { anaemia; raise haemoglobin } \\
\text { level to at least } 10.0 \mathrm{~g} / \mathrm{dL}\end{array}$ & $100 ; 100$ & 50 (50.0); $37(37.0)$ & 30 day mortality \\
\hline Walsh 2013, UK (multicentre) & Critical care $^{\star}$ & $70 \mathrm{~g} / \mathrm{L} ; \mathrm{L}: 90 \mathrm{~g} / \mathrm{L}$ & $51 ; 49$ & $17(33.3) ; 15(30.6)$ & $\begin{array}{l}\text { Feasibility: difference in mean } \\
\text { haemoglobin concentration during } \\
\text { intervention period }\end{array}$ \\
\hline
\end{tabular}

syndrome were excluded ${ }^{56} 57$ supported the result of the primary analysis (1.10, 0.88 to 1.37 ). The GRADE quality of evidence was judged to be moderate (table 2).

Two trials also presented mortality for all patients at 60 days $^{5567}$ and three trials at 90 days $^{666869}$; however, we were only able to extract data on patients with cardiovascular disease from one trial (60 day mortality: restrictive transfusion 66/1007 (6.6\%) $v$ liberal transfusion $76 / 998(7.6 \%)) .55$

\section{Adverse events: cardiovascular}

Nine trials presented data (2609 patients) on new cardiovascular events. ${ }^{54-59}$ 66-68 The definition of myocardial infarction varied between trials (see supplementary table E4). All trials except two (definition unclear) ${ }^{5866}$ required electrocardiographic changes with an increase or decrease of cardiac biomarkers using the third universal definition of myocardial infarction. ${ }^{7}$ Five trials also required symptoms consistent with myocardial ischaemia. ${ }^{1755576768}$ The diagnosis of myocardial infarction was made by investigators in four trials, 55566768 clinicians in three trials, ${ }^{575966}$ and was unclear in two trials. ${ }^{5458}$ The diagnosis was blinded in four trials, ${ }^{55566768}$ unblinded in three trials, ${ }^{575966}$ and unclear in two trials. ${ }^{5458}$ The incidence of acute coronary syndrome (fig 3) ranged from $0 \%{ }^{6667}$ to $20.4 \%{ }^{56}$ in the restrictive transfusion arms and $0 \% 0^{57596667}$ to $11.1 \%{ }^{56}$ in the liberal transfusion arms. There was evidence of an increased incidence of acute coronary syndrome in patients in the restrictive transfusion arms compared with patients in the liberal transfusion arms (risk ratio $1.78,95 \%$ confidence interval 1.18 to $2.70, \mathrm{P}=0.01, \mathrm{I}^{2}=0 \%$, restrictive transfusion: 59 events/1319 patients $v$ liberal transfusion: 32 events/1290 patients). This corresponds to 4.6 episodes of acute coronary syndrome per 100 patients when using restrictive strategies and 2.7 per 100 patients when using liberal strategies. To prevent one episode of acute coronary syndrome, 52 patients would need to be treated with a liberal transfusion strategy.

For the analysis of patients with acute pulmonary oedema, three trials had a higher incidence of acute pulmonary oedema in the liberal transfusion arms, ${ }^{575866}$ whereas one trial had a higher incidence in the restrictive transfusion arm. ${ }^{56}$ There was no evidence of a different risk of acute pulmonary oedema in the restrictive transfusion arms compared with liberal transfusion arms (risk ratio $0.63,95 \%$ confidence interval 0.22 to 1.81, $\mathrm{P}=0.39, \mathrm{I}^{2}=60 \%$, fig 3, restrictive: 24 events $/ 309$ patients $v$ liberal: 47 events/340 patients). Two trials reported no new episodes of acute pulmonary oedema, ${ }^{667}$ and there was only one episode of acute pulmonary oedema, in one trial. ${ }^{59}$ Cerebrovascular and thrombotic events were rare in both restrictive and liberal transfusion arms and meta-analysis was not possible.

A sensitivity analysis excluding trials that did not stratify randomisation based on cardiovascular disease, had minimal impact on the estimates for the outcomes of acute coronary syndrome and acute pulmonary oedema. The GRADE quality of evidence was judged low for acute coronary syndrome mainly because of the serious risk of bias in outcome assessment (table 2). Sensitivity analysis excluding the two acute coronary syndrome trials ${ }^{5657}$ had minimal impact 

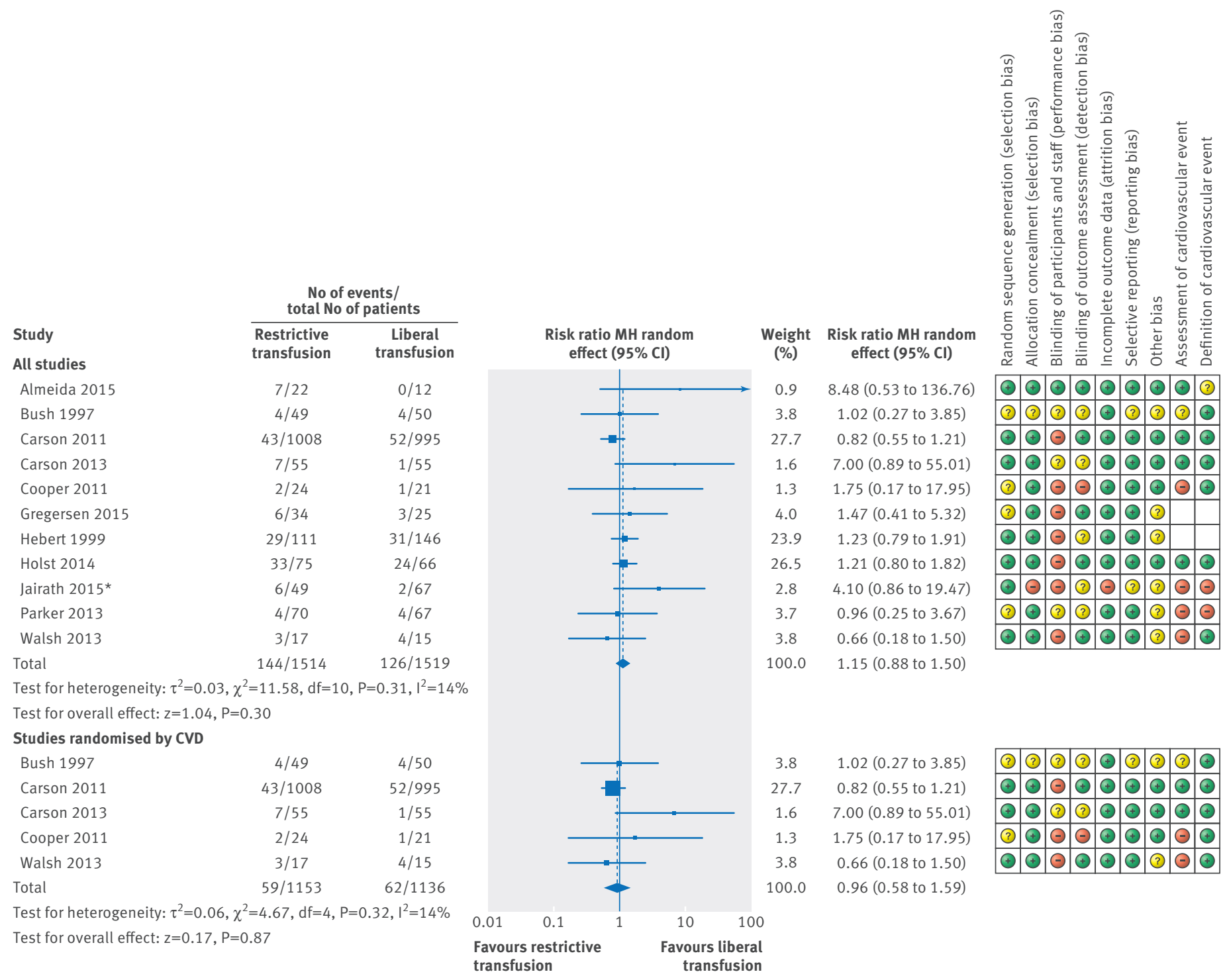

Fig 2 Forest plot of risk ratios for 30 day mortality with risk of bias assessment for each study. *Additional risk of bias assessed as to completeness of patients recruited into clusters (this was graded as low risk). CVD=cardiovascular disease

on the point estimates for this outcome of new acute coronary syndrome (risk ratio $1.76,1.10$ to 2.81 ). The risk of acute coronary syndrome remained higher for the restrictive group on removal of the largest trial, which had 2016 participants (risk ratio 2.07, 1.02 to 4.23)..$^{55}$

\section{Adverse events: general}

Non-cardiovascular adverse events were reported across eight trials (see supplementary table E5).17545557596669 These endpoints were described differently in each paper owing to the different clinical settings and rationale of the trials.

Six trials reported hospital length of stay for patients with cardiovascular disease. ${ }^{54-59} 69$ The difference between the restrictive and liberal transfusion arms was not significant (mean difference 1.24 days, 95\% confidence interval -1.0 to $3.48, \mathrm{P}=0.28$, see supplementary figure E2). Three trials reported in-hospital infection, but the number of events was small (see supplementary table E2). ${ }^{566671}$ One trial found no differences in organ support in a retrospective analysis of patients with cardiovascular disease (L Holst, personal communication, 2016), ${ }^{68}$ and no events were classified as adverse transfusion reactions.

\section{Risk of bias}

The risk of bias is summarised in figures 2 and 3 . The main category for high risk of bias was the lack of blinding of participants, clinical staff, and research staff (identified in six trials). ${ }^{265557-5968}$ The diagnosis of cardiovascular events is difficult in many of the settings in which trials took place, such as during critical illness, increasing the risk of performance bias in conjunction with unblinded outcome assessors. Another potential explanation for differing prevalence between trials was variations in definitions used (see supplementary table E4). Cardiovascular events were diagnosed by investigators in five trials ${ }^{56-586768}$ and 


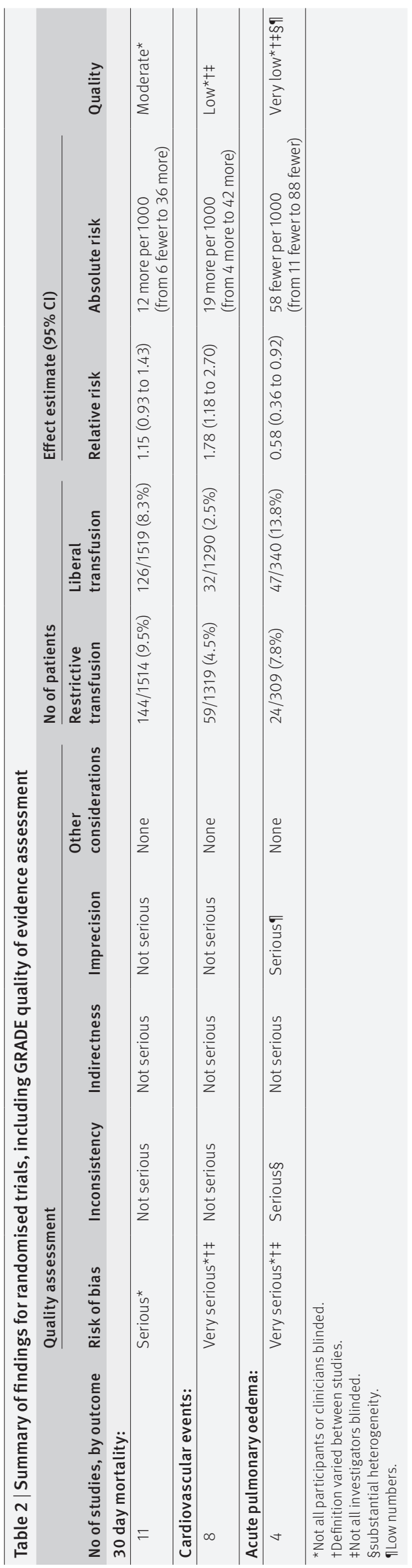

unblinded clinicians in three trials. ${ }^{575966}$ The criteria for myocardial infarction were clearly defined in seven trials ${ }^{54-57596768}$ and were unclear in two trials. ${ }^{5866}$ In only one trial was both the definition and the outcome assessment at high risk of bias, ${ }^{66}$ but no new cardiovascular events were diagnosed in this trial and its removal did not alter the analysis.

\section{Discussion}

We identified data from 11 randomised trials that enrolled 3033 patients with cardiovascular disease in whom mortality data were available at 30 days, and nine trials that enrolled 2609 patients with cardiovascular disease in whom data on new cardiovascular events were available. A restrictive transfusion threshold was associated with an increased risk of acute coronary syndrome in patients with cardiovascular disease, with low heterogeneity between trials (moderate quality of evidence as assessed by GRADE). We found no evidence of a difference in 30 day mortality between restrictive and liberal transfusion groups. The incidence of pulmonary oedema did not differ between the transfusion thresholds, but heterogeneity was present between trials and the GRADE quality of evidence was judged to be very low. The length of hospital stay did not differ between restrictive and liberal transfusion strategies, and other outcomes were rare, with inadequate data for meta-analysis.

This is the first systematic review to specifically deal with clinical outcomes for patients with acute and chronic cardiovascular disease managed with restrictive or liberal transfusions and not including patients undergoing cardiac surgery. Several well conducted systematic reviews have been published, but these did not examine patient subgroups with cardiovascular disease. ${ }^{11-13}$ The inclusion of heterogeneous populations in trials can mask potentially divergent effects in subpopulations, ${ }^{72}$ and effects may be amplified when trials are combined for meta-analyses. The 2012 Cochrane review recommended the use of a restrictive transfusion trigger but suggested caution in patients from high risk groups such as those with acute coronary syndrome. ${ }^{13}$ Similar statements were made by Holst ${ }^{12}$ and Brunskill ${ }^{11}$ in their systematic reviews of transfusion thresholds for sepsis and patients undergoing surgery for hip fracture, respectively. Evidence is limited by the under-representation of patients with cardiovascular disease in many randomised controlled trials. For example, only $20 \%$ of patients enrolled in a large critical care trial had cardiovascular disease, compared with $29 \%$ of excluded patients. ${ }^{58}$ Similarly, only $14 \%$ of patients enrolled in a trial of septic shock had cardiovascular disease, ${ }^{68}$ whereas observational trials suggest around $25-30 \%$ of critical care populations may have coexisting cardiac disease. ${ }^{873}$

The previous reviews in heterogeneous populations suggest overall trends towards lower 30 day mortality with restrictive transfusion strategies (range of risk ratio 0.85 , 95\% confidence interval 0.70 to $1.03^{13}$ to 0.92 , 0.67 to 1.26$),{ }^{11}$ whereas the effect we observed in 

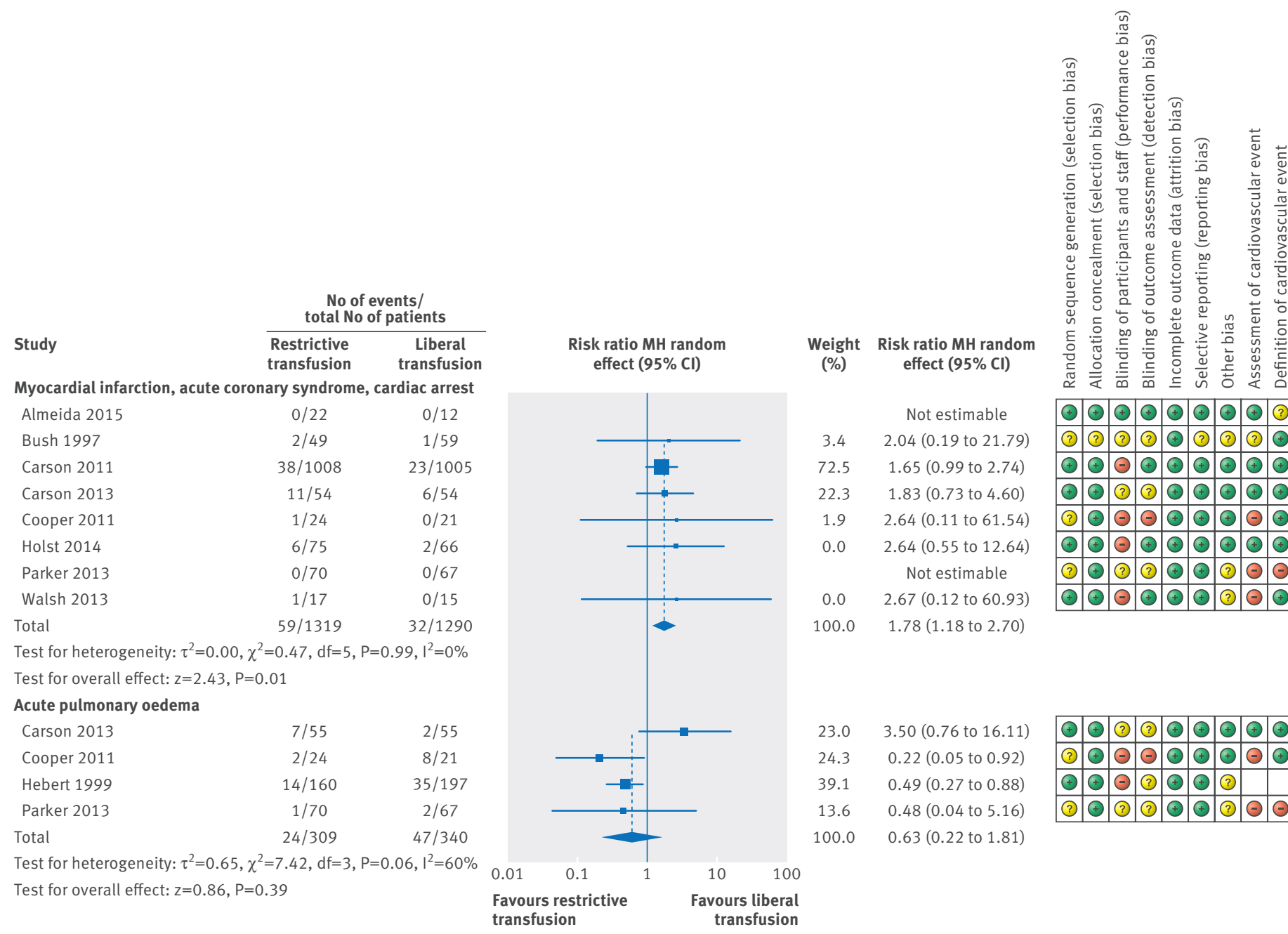

Myocardial infarction, acute coronary syndrome, cardiac arrest

ratio $\mathrm{MH}$ random

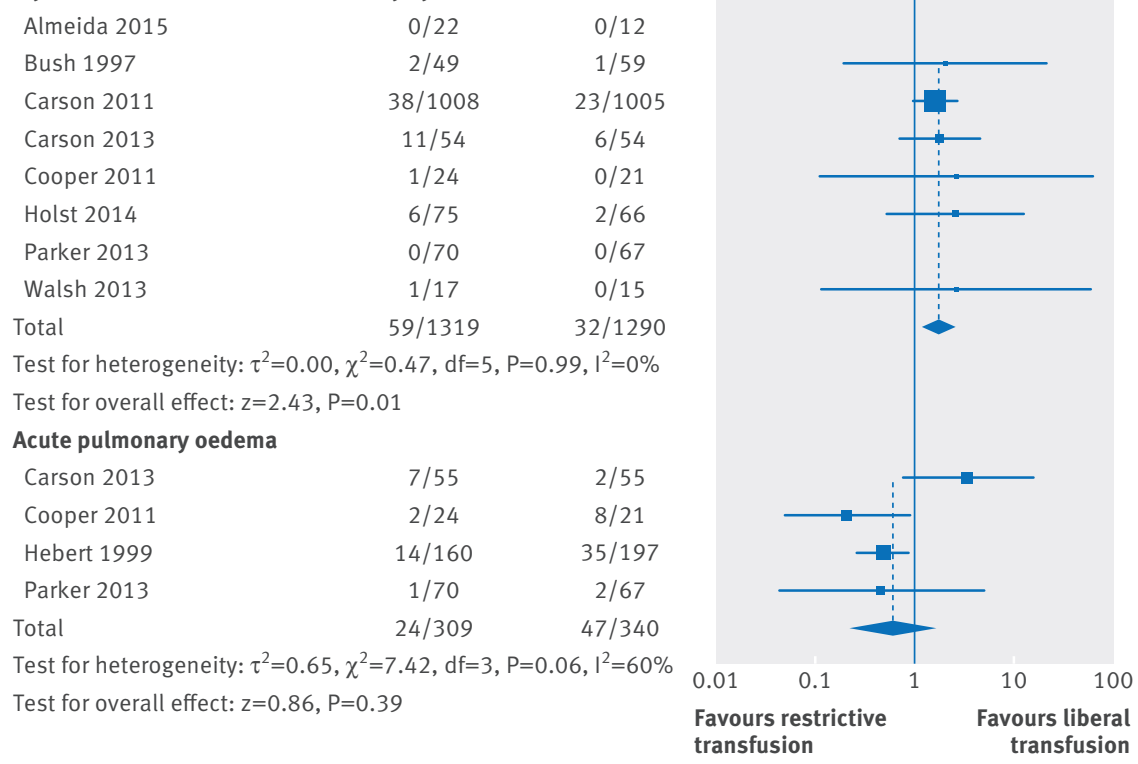

patients with cardiovascular disease was in the direction favouring liberal transfusion, but without statistical significance (1.10, 0.84 to 1.44$)$. We specifically excluded trials in cardiac surgery as this is comprises a distinct group of patients with a cardiovascular risk that has been altered profoundly by their procedure. A recent large multicentre randomised controlled trial in cardiac surgery ${ }^{74}$ found no difference in a composite morbidity outcome, but the 90 day mortality rate was significantly higher in the restrictive transfusion group compared with liberal transfusion group. A recent systematic review and meta-analysis restricted to trials in cardiac surgery also found increased mortality with restrictive transfusion thresholds. ${ }^{18}$ Another systematic review ${ }^{75}$ of perioperative randomised controlled trials of transfusion practice (including cardiac surgery) also found higher mortality with a restrictive transfusion threshold, although the prevalence of cardiovascular disease in these trials was uncertain. These data suggest that the presence of cardiovascular disease may modify the effect of transfusion practice on clinical outcomes considerably, and the data highlight the need for better evidence for this prevalent patient group.
We found that new onset acute coronary syndrome occurred more often with restrictive transfusion strategies. The pooled estimates were $2.7 \%$ for liberal transfusion compared with $4.6 \%$ for restrictive transfusion (number needed to treat approximately 52 to prevent an acute coronary syndrome with more liberal transfusion). The variation in patient populations, transfusion strategies compared, and method of ascertaining acute coronary syndrome create substantial uncertainty in these estimates, but the heterogeneity between trials was low. The estimate of effect was the same when the largest trial was removed. Importantly, for most included cases the restrictive transfusion threshold was $80 \mathrm{~g} / \mathrm{L}$ compared with a liberal transfusion threshold of $100 \mathrm{~g} / \mathrm{L}$. These findings suggest that a transfusion threshold of $70 \mathrm{~g} / \mathrm{L}$, which is widely recommended as the "default" threshold, may not be as safe as higher thresholds for preventing acute coronary syndrome in patients with cardiovascular disease. The safest haemoglobin threshold is uncertain and may be patient specific, but we have shown potential for harm with restrictive triggers less than $80 \mathrm{~g} / \mathrm{L}$. Further trials are needed to inform the optimal transfusion strategy in patients with cardiovascular disease. Myocardial injury 
could have an effect on other important clinical outcomes such as length of hospital stay, quality of life, longer term mortality, and healthcare costs, but few trials have measured these outcomes. These outcomes, together with cost effectiveness, should be included in future research, particularly as the cost of blood transfusions is relatively low and even in the liberal transfusion arm in this review patients typically received only two or three units. Our review highlights the variability in diagnostic definitions of acute coronary syndrome and the potential for ascertainment bias in clinical trials where blinding of intervention groups is difficult. This resulted in low evidence of quality according to GRADE, and it highlights the need for further high quality research.

We found no effect on acute pulmonary oedema, but the numbers of trials and patients in whom this outcome was reported was small and the findings were heterogeneous. Acute pulmonary oedema can result from multiple causes, including transfusion associated circulatory overload, and the potential for an effect in a different direction from acute coronary syndrome made it important to consider these outcomes separately rather than to include them as a composite. Future trials should standardise diagnostic methods for both acute coronary syndrome and acute pulmonary oedema and attempt to blind outcome assessors to group allocation.

\section{Limitations of this review}

Our review has several limitations. There was clinical diversity between trial populations-for example, between orthopaedic surgery and critical care. The risk-benefit balance may vary between clinical situations (for example, as a result of the degree and duration of physiological stress). The restrictive and liberal transfusion thresholds varied between trials, and the cut-off values actually overlapped (restrictive threshold 70-97 g/L; liberal threshold 90-113 g/L), which reduces the validity of pooling data across all trials. Exposure to anaemia would have been considerably longer in the four intensive care unit trials than in the four surgical trials, in which the presence of anaemia would have been relatively short. Definitions of cardiovascular disease varied, and inclusion criteria for some trials were restricted to ischaemic heart disease or acute coronary syndrome. However, the direction of effect was consistently in favour of a liberal transfusion threshold for reducing new acute coronary syndrome events across the trials. Finally, some authors did not respond to our request for data on their participants with cardiovascular disease, and this reduced the precision of our point estimates.

\section{Conclusion}

This review of available evidence suggests that for anaemic patients with cardiovascular disease, the use of restrictive transfusion thresholds (typically a haemoglobin level of 70-80 g/L) is associated with higher rates of acute coronary syndrome than more liberal transfusion thresholds (typically 90-100 g/L). No effects on mortality or other important outcomes were found. The currently available quality of evidence for all outcomes was low. These data support the use of a more liberal transfusion threshold (>80 g/L) for patients with both acute and chronic cardiovascular disease, until adequately powered high quality randomised trials have been undertaken in this patient population.

\section{AUTHOR AFFILIATIONS}

\section{${ }^{1}$ Centre for Inflammation Research, University of Edinburgh,} Edinburgh, UK

${ }^{2}$ Critical Care Department, Royal Infirmary Edinburgh, Edinburgh, UK ${ }^{3}$ Systematic Review Initiative, NHS Blood and Transplant, John Radcliffe Hospital, Oxford, UK

${ }^{4}$ Centre for Statistics in Medicine, University of Oxford, Oxford, UK ${ }^{5}$ Department of Intensive Care, Copenhagen University Hospital, Rigshospitalet, Copenhagen, Denmark

${ }^{6}$ Department of Orthopaedics, Peterborough and Stamford Hospitals NHS Trust, Peterborough, UK

'Department of Geriatrics, Aarhus University, Aarhus, Denmark ${ }^{8}$ Surgical Intensive Care Unit and Department of Anesthesiology, Cancer Institute, Hospital das Clinicas da Faculdade de Medicina da Universidade de Sao Paulo, Sao Paulo, Brazil

${ }^{9}$ Department of Haematology, NHS Blood and Transplant/Oxford University Hospitals NHS Trust, Oxford, UK

Contributors: ABD, RO'D, SB, MT, TSW, and SJS conceived and designed the study. Acquisition, analysis, or interpretation of the data: $A B D, R O$ 'D, SB, CD, TSW, SJS, LH, MP, and MG acquired, analyses, and interpreted the data. ABD, R'OD, SB, TSW, and SJS drafted the manuscript. ABD and MT carried out the statistical analysis. TSW and SIS supervised the study. ABD had full access to all of the data in the study and takes responsibility for the integrity of the data and the accuracy of the data analysis.

Funding: None.

Competing interests: All authors have completed the ICMJE uniform disclosure form at www.icmje.org/coi_disclosure.pdf and declare: no support from any organisation for the submitted work; no financial relationships with any organisations that might have an interest in the submitted work in the previous three years; no other relationships or activities that could appear to have influenced the submitted work.

Ethical approval: Not required

Data sharing: No additional data available.

Transparency: ABD affirms that this manuscript is an honest, accurate, and transparent account of the study being reported; that no important aspects of the study have been omitted; and that any discrepancies from the study as planned (and, if relevant, registered) have been explained.

This is an Open Access article distributed in accordance with the Creative Commons Attribution Non Commercial (CC BY-NC 3.0) license, which permits others to distribute, remix, adapt, build upon this work non-commercially, and license their derivative works on different terms, provided the original work is properly cited and the use is noncommercial. See: http://creativecommons.org/licenses/by-nc/3.0/.

1 British Heart Foundation. Cardiovascular Disease Statistics 2015. Oxford; 2015. https://www.bhf.org.uk/publications/statistics/ cvd-stats-2015

2 Vincent JL, Baron J-F, Reinhart K, et al. ABC (Anemia and Blood Transfusion in Critical Care) Investigators. Anemia and blood transfusion in critically ill patients. JAMA 2002;288:1499-507.

3 Carson J, Duff A, Poses R, et al. Effect of anaemia and cardiovascular disease on surgical mortality and morbidity. Lancet 1996;348:1055-60.

4 Wu W-C, Rathore SS, Wang Y, Radford MJ, Krumholz HM. Blood transfusion in elderly patients with acute myocardial infarction. N Engl IMed 2001:345:1230-6.

5 Horwich TB, Fonarow GC, Hamilton MA, MacLellan WR, Borenstein J. Anemia is associated with worse symptoms, greater impairment in functional capacity and a significant increase in mortality in patients with advanced heart failure. J Am Coll Cardiol 2002;39:1780-6.

6 Sabatine MS, Morrow DA, Giugliano RP, et al. Association of hemoglobin levels with clinical outcomes in acute coronary syndromes. Circulation 2005;111:2042-9. 
7 Thygesen K, Alpert JS, Jaffe AS, et al. Joint ESC/ACCF/AHA/WHF Task Force for Universal Definition of Myocardial Infarction. Authors/ Task Force Members Chairpersons; Biomarker Subcommittee; ECG Subcommittee; Imaging Subcommittee; Classification Subcommittee; Intervention Subcommittee; Trials \& Registries Subcommittee; Trials \& Registries Subcommittee; Trials \& Registries Subcommittee; Trials \& Registries Subcommittee; ESC Committee for Practice Guidelines (CPG); Document Reviewers. Third universal definition of myocardial infarction. J Am Coll Cardiol 2012;60:1581-98

8 Ostermann M, Lo J, Toolan M, et al. A prospective study of the impact of serial troponin measurements on the diagnosis of myocardial infarction and hospital and six-month mortality in patients admitted to ICU with non-cardiac diagnoses. Crit Care 2014;18:R62.

9 Nagele P, Brown F, Gage BF, et al. High-sensitivity cardiac troponin $T$ in prediction and diagnosis of myocardial infarction and long-term mortality after noncardiac surgery. Am Heart J 2013;166:325-332.e1

10 Botto F, Alonso-Coello P, Chan MT, et al. Myocardial injury after noncardiac surgery: a large, international, prospective cohort study establishing diagnostic criteria, characteristics, predictors, and 30-day outcomes. Anesthesiology 2014;120:564-78.

11 Brunskill SJ, Millette SL, Shokoohi A, et al. Red blood cell transfusion for people undergoing hip fracture surgery. Cochrane Database Syst Rev 2015;4:CD009699.

12 Holst LB, Petersen MW, Haase N, Perner A, Wetterslev J. Restrictive versus liberal transfusion strategy for red blood cell transfusion: systematic review of randomised trials with meta-analysis and trial sequential analysis. BMJ 2015;350:h1354.

13 Carson JL, Carless PA, Hebert PC. Transfusion thresholds and other strategies for guiding allogeneic red blood cell transfusion. Cochrane Database Syst Rev 2012;4:CD002042.

14 Association of Anaesthetists of Great Britain and Ireland. Blood Transfusion and the Anaesthetist: Red Cell Transfusion 2. London; 2008.

15 Carson JL, Grossman BJ, Kleinman S, et al. Clinical Transfusion Medicine Committee of the AABB. Red blood cell transfusion: a clinical practice guideline from the AABB*. Ann Intern Med 2012;157:49-58

16 Norfolk DD, ed. Joint UK blood transfusion and tissue transplantation services professional advisory committee. Handbook of Transfusion Medicine.TSO, 2013.

17 Retter A, Wyncoll D, Pearse R, et al. British Committee for Standards in Haematology. Guidelines on the management of anaemia and red cell transfusion in adult critically ill patients. Br I Haematol 2013;160:445-64

18 Patel NN, Avlonitis VS, Jones HE, Reeves BC, Sterne JA, Murphy GJ. Indications for red blood cell transfusion in cardiac surgery: a systematic review and meta-analysis. Lancet Haemato 2015;2:e543-53.

19 National Institute for Health and Clinical Excellence. Transfusion: NICE guideline NG24. 2015. http://www.nice.org.uk/guidance/ng24/ evidence/full-guidance-2177160733

20 Moher D, Liberati A, Tetzlaff J, Altman DG. PRISMA Group. Preferred reporting items for systematic reviews and meta-analyses: the PRISMA statement. PLoS Med 2009;6:e1000097.

21 Docherty A, O'Donnell R, Brunskill S, Doree C, Walsh TS, Stanworth S. Transfusion thresholds in patients with Cardiovascular Disease (non-cardiac surgery). PROSPERO. 2014. http://www.crd.york.ac.uk/ PROSPERO/display_record.asp?ID=CRD42014014251

22 Wilkinson KL, Brunskill S), Dorée C, et al. The clinical effects of red blood cell transfusions: an overview of the randomized controlled trials evidence base. Transfus Med Rev 2011:25:145-155.e2.

23 Higgins J, Green S, (editors). Cochrane Handbook for Systematic Reviews of Interventions Version 5.1.0 (updated March 2011). The Cochrane Collaboration 2011. www.cochrane-handbook.org

24 Shunemann H, Oxman A, Vist G, Higgins J, Deeks J, Glasziou P. Interpreting results and drawing conclusions. In: The Cochrane Collaboration. Cochrane Handbook for Systematic Reviews of Interventions Version 510 [updated March 2011]. 2011.

25 The Cochrane Collaboration. Review Manager(RevMan). The Nordic Cochrane Centre, 2014

26 Jairath V, Kahan BC, Gray A, et al. Restrictive versus liberal blood transfusion for acute upper gastrointestinal bleeding (TRIGGER): a pragmatic, open-label, cluster randomised feasibility trial. Lancet 2015;386:137-44.

27 Wu Q. Clinical research of restrictive transfusion in elderly patients undergoing orthopedic surgery. www.chictr.org.cn/showprojen. aspx?proj=8714

28 Tay J, Tinmouth A, Fergusson D, Allan D. Transfusion of red cells in hematopoietic stem cell transplantation (TRIST): study protocol for a randomized controlled trial. Trials 2011;12:207

29 Buckstein R. Red blood cell transfusion thresholds and QOL in MDS (EnhanceRBC). https://clinicaltrials.gov/ct2/show/NCT01079247.

30 Palmieri TL. A trial of restrictive versus traditional blood transfusion practices in burn patients. https://clinicaltrials.gov/ct2/show/ NCT01079247.
31 Matot I. Restrictive versus liberal red cell transfusion strategy in orthopedic-oncology patients undergoing surgery - a randomized controlled study. https://clinicaltrials.gov/ct2/show/NCT01491308.

32 Grover M, Talwalkar S, Casbard A, et al. Silent myocardial ischaemia and haemoglobin concentration: a randomized controlled trial of transfusion strategy in lower limb arthroplasty. Vox Sang 2006;90:105-12.

33 Zheng $\mathrm{H}$, Wu J-J, Wang J. Evaluation of effectiveness and analysis of goal-directed blood transfusion in peri-operation of major orthopedic surgery in elderly patients. Exp Ther Med 2013:5:511-6.

34 Webert KE, Cook RJ, Couban S, et al. A multicenter pilot-randomized controlled trial of the feasibility of an augmented red blood cell transfusion strategy for patients treated with induction chemotherapy for acute leukemia or stem cell transplantation. Transfusion 2008;48:81-91.

35 Prick BW, Jansen AJ, Steegers EA, et al. Transfusion policy after severe postpartum haemorrhage: a randomised non-inferiority trial. BJOG 2014; $121: 1005-14$

36 Nielsen K, Dahl B, Johansson PI, Henneberg SW, Rasmussen LS Intraoperative transfusion threshold and tissue oxygenation: a randomised trial. Transfus Med 2012;22:418-25.

37 Liu DX, Liu J, Zhang F, Zhang Q-Y, Xie M, Zhu Z-Q. Randomized controlled study on safety and feasibility of transfusion trigger score of emergency operations. Chin Med I (Engl) 2015:128:1801-8.

38 Koshy M, Burd L, Wallace D, Moawad A, Baron J. Prophylactic red-cell transfusions in pregnant patients with sickle cell disease. A randomized cooperative study. N Engl / Med 1988;319:1447-52.

39 Haberkern CM, Neumayr LD, Orringer EP, et alCholecystectomy in sickle cell anemia patients: perioperative outcome of 364 cases from the National Preoperative Transfusion Study. Blood 1997;89:1533-42.

40 Bergamin F, Almeida J, Park C, Osawa E, Silva J, Galas F, et al. Transfusion requirements in septic shock patients: a randomized controlled trial. Crit Care 2014;18:112. http://link.springer.com/ article/10.1186\%2Fcc13302.

41 Blair SD, Janvrin SB, McCollum CN, Greenhalgh RM. Effect of early blood transfusion on gastrointestinal haemorrhage. Br J Surg 1986;73:783-5.

42 Fortune JB, Feustel PJ, Saifi J, Stratton HH, Newell JC, Shah DM. Influence of hematocrit on cardiopulmonary function after acute hemorrhage. I Trauma 1987:27:243-9.

43 Lotke PA, Barth P, Garino JP, Cook EF. Predonated autologous blood transfusions after total knee arthroplasty: immediate versus delayed administration. J Arthroplasty 1999:14:647-50.

44 Robertson CS, Hannay HJ, Yamal J-M, et al. Epo Severe TBI Trial Investigators. Effect of erythropoietin and transfusion threshold on neurological recovery after traumatic brain injury: a randomized clinical trial. JAMA 2014:312:36-47.

45 Villanueva C, Colomo A, Bosch A, et al. Transfusion strategies for acute upper gastrointestinal bleeding. N Engl J Med 2013; 368:11-21.

46 Zygun DA, Nortje J, Hutchinson PJ, Timofeev I, Menon DK, Gupta AK. The effect of red blood cell transfusion on cerebral oxygenation and metabolism after severe traumatic brain injury. Crit Care Med 2009:37:1074-8.

47 Colomo A, Hernandez-Gea V, Muniz-Diaz E, Madoz P, Aracil C, Alarez-Urturi C. Transfusion strategies in patients with cirrhosis and acute gastrointestinal bleeding[abstract]. Hepatology 2008;48(Suppl):413A.

48 Hochain P, Merle V, Tuil S, et al. Transfusion for variceal bleeding in cirrhotic patients[letter]. Gut 1996;38:154.

49 So-Osman C. A restrictive transfusion trigger is a method for blood saving in elective orthopaedic surgery[abstract]. Vox Sang 2004;87(Suppl 3):52.

50 Weiss GB, Patten E, Alperin JB, et al. Hypertransfusion for adult acute leukaemia[letter]. Lancet 1982;1:105

51 Park SH, Nam E, Bang SM, Cho EK, Shin DB, Lee JH. A randomized tria of anemia correction with two different hemoglobin targets in the first-line chemotherapy of advanced gastric cancer. Cancer Chemother Pharmacol 2008;62:1-9.

52 Villarejo F, Rizzolo M, Lópéz E, Domeniconi G, Arto G, Apezteguia C. [Acute anemia in high digestive hemorrhage. Margins of security for their handling without transfusion of red globules]. Acta Gastroenterol Latinoam 1999;29:261-70.

53 Palmer J, Maciver C, Scott R, Picken M, McClelland D, Keating J, et al Hip fracture and transfusion trial (HATT) [abstract]. Transfus Med 1998;8:52.

54 Bush RL, Pevec WC, Holcroft JW. A prospective, randomized trial limiting perioperative red blood cell transfusions in vascular patients. Am J Surg 1997;174:143-8.

55 Carson JL, Terrin ML, Noveck H, et al. FOCUS Investigators. Liberal or restrictive transfusion in high-risk patients after hip surgery. N Engl] Med 2011;365:2453-62

56 Carson JL, Brooks MM, Abbott JD, et al. Liberal versus restrictive transfusion thresholds for patients with symptomatic coronary artery disease. Am HeartJ 2013;165:964-971.e1. 
57 Cooper HA, Rao SV, Greenberg MD, et al. Conservative versus liberal red cell transfusion in acute myocardial infarction (the CRIT Randomized Pilot Study). Am / Cardiol 2011;108:1108-11.

58 Hébert PC, Wells G, Blajchman MA, et al. A multicenter, randomized, controlled clinical trial of transfusion requirements in critical care. Transfusion Requirements in Critical Care Investigators, Canadian Critical Care Trials Group. N Engl J Med 1999;340:409-17.

59 Walsh TS, Boyd JA, Watson D, et al. RELIEVE Investigators. Restrictive versus liberal transfusion strategies for older mechanically ventilated critically ill patients: a randomized pilot trial. Crit Care Med 2013;41:2354-63

60 Carson JL, Terrin ML, Barton FB, et al. A pilot randomized trial comparing symptomatic vs. hemoglobin-level-driven red blood cell transfusions following hip fracture. Transfusion 1998;38:522-9.

61 Fan Y-X, Liu F-F, Jia M, et al. Comparison of restrictive and libera transfusion strategy on postoperative delirium in aged patients following total hip replacement: a preliminary study. Arch Gerontol Geriatr 2014;59:181-5

62 Hébert PC, Wells G, Marshall J, et al. Canadian Critical Care Trials Group. Transfusion requirements in critical care. A pilot study. JAMA 1995;273:1439-44.

63 Foss NB, Kristensen MT, Jensen PS, Palm H, Krasheninnikoff M Kehlet $\mathrm{H}$. The effects of liberal versus restrictive transfusion thresholds on ambulation after hip fracture surgery. Transfusion 2009;49:227-34.

64 Mazza BF, Freitas FGR, Barros MMO, Azevedo LCP, Machado FR. Blood transfusions in septic shock: is $7.0 \mathrm{~g} / \mathrm{dL}$ really the appropriate threshold?Rev Bras Ter Intensiva 2015;27:36-43.

65 Nielsen K, Johansson PI, Dahl B, et al. Perioperative transfusion threshold and ambulation after hip revision surgery--a randomized trial. BMC Anesthesiol 2014:14:89.

66 Parker MJ. Randomised trial of blood transfusion versus a restrictive transfusion policy after hip fracture surgery. Injury 2013;44:1916-8.
67 De Almeida JP, Vincent JL, Galas FR, et al. Transfusion requirements in surgical oncology patients: a prospective, randomized controlled trial. Anesthesiology 2015;122:29-38.

68 Holst LB, Haase N, Wetterslev J, et al. TRISS Trial Group Scandinavian Critical Care Trials Group. Lower versus higher hemoglobin threshold for transfusion in septic shock. N Engl J Med 2014;371:1381-91.

69 Gregersen M, Borris LC, Damsgaard EM. Postoperative blood transfusion strategy in frail, anemic elderly patients with hip fracture: the TRIFE randomized controlled trial. Acta Orthop 2015;86:363-72.

70 So-Osman C, Nelissen R, Te Slaa R, Coene L, Brand R. Brand A. A randomized comparison of transfusion triggers in elective orthopaedic surgery using leucocyte-depleted red blood cells. Vox Sang 2010;98:56 -64

71 Gregersen M, Damsgaard EM, Borris LC. Blood transfusion and risk of infection in frail elderly after hip fracture surgery: the TRIFE randomized controlled trial. Eur / Orthop Surg Traumatol.Springer Paris, 2015.

72 Deans KJ, Minneci PC, Suffredini AF, et al. Randomization in clinical trials of titrated therapies: unintended consequences of using fixed treatment protocols. Crit Care Med 2007;35:1509-16.

73 Walsh TS, McClelland DB, Lee RJ, et al. ATICS Study Group. Prevalence of ischaemic heart disease at admission to intensive care and its influence on red cell transfusion thresholds: multicentre Scottish Study. Br J Anaesth 2005;94:445-52.

74 Murphy GJ, Pike K, Rogers CA, et al. TITRe2 Investigators. Liberal or restrictive transfusion after cardiac surgery. N Engl I Med 2015;372:997-1008.

75 Fominskiy E, Putzu A, Monaco F, et al. Liberal transfusion strategy improves survival in perioperative but not in critically ill patients. A meta-analysis of randomised trials. BrJ Anaesth 2015;115:511-9.

Web extra: Online data supplement 